\title{
THE NONFILTRABILITY OF TYPHUS-FEVER VIRUS *
}

\author{
Pfiter K. OLITSKY \\ From the Pathological Laboratory of the Mount Sinai Hospital, New York
}

In a communication dealing with the etiology of typhus fever, Plotz ${ }^{1}$ presented a review of the evidence which led him to believe that the virus is nonfiltrable. No effort was made at that time to give all the facts leading to this conclusion. It is the purpose of my paper to analyze the previous work, and to present new evidence bearing on the nonfiltrability of typhus virus.

The basis for the assertion that the virus is filtrable is a single, very doubtful, experiment of Nicolle, Conor, and Conseil. ${ }^{2}$ As additional support, the single incomplete experiment of $W_{\text {ilder }}{ }^{3}$ is usually quoted. Thus, Wolbach ${ }^{4}$ classified typhus among the filtrable viruses on such evidence; so did Löffler ${ }^{5}$ and Lipschütz. ${ }^{6}$ R. Kraus ${ }^{\top}$ stated dogmatically that typhus-fever virus was filtrable, while Park and Williams ${ }^{8}$ asserted that there was "the possibility of the virus having a filtrable stage." Jordan ${ }^{9}$ quite recently stated that "inoculation with filtered blood does, however, render monkeys refractory to further infection, according to the testimony of several observers."

In reviewing the original sources of the assumption that the virus is filtrable I shall analyze Nicolle's work first. All his work on this problem may be summarized in a résumé of 5 series of experiments.

The first series comprised 4 monkeys -1 injected with unfiltered, the other 3 with filtered typhus serum. All failed to react, except 'Bonnet 47,' which was injected with filtered serum; this animal showed an elevation of one-half degree (Centigrade) between the 16th and 18 th days after inoculation. After a time all these monkeys were reinoculated with typhus virus and all except Bonnet 47 developed the

* Received for publication December 2, 1916. Work done under the tenure of a Ceorge Blumenthal Ir. fellowship in pathology.

1 Plotz, Olitsky, and Baehr, Jour. Infect. Dis., 1915, 17, p. 1.

$z$ Ann. de l'Inst. Pasteur, 1911, 25, p. 97. Compt. rend. Acad. d. sc., 1911, 153, p. 1522.

3 Jour. Infect. Dis., 1911,9 , p. 9.

4 Jour. Med. Research, 1912-1913, 22, p. 1.

s Tr. Internat. Cong. Med., London, 1913, Lect. 4, p. 35.

* Kolle u. Wassermann, Handb. d. pathogen. Mikroorganismen, 1913, 8, p. 353.

7 Wien. klin. Wchnschr., 1914, 27, p. 925.

8 Pathogenic Microorganisms, 1914.

- Text-Book of General Bacteriology, 1916. 
fever. From this single experiment (which he has never been able to confirm). Nicolle concluded that the virus is filtrable.

In the light of my experience it appears that Nicolle was dealing with avirulent blood - certainly his control test shows this. Also, the first reaction in Bonnet 47 can hardly be called typhus fever-- a rise in temperature of 1 to 2 degrees for 1 or 2 days is quite common in normal monkeys. The animal remained refractory to a subsequent injection of virulent blood either because it was a naturally immune monkey, or because it was not inoculated of ten enough. Anderson and Goldberger ${ }^{10}$ showed that $221 / 2 \%$ of the monkeys used failed to react to virulent blood $; 31 \% 2 \%$ resisted 3 or more successive inoculations, and were not immunized by these repeated injections. This conforms with our experience at Mount Sinai Hospital Jaboratory. A conclusion. based on Nicolle's uncertain and uncontrolled series of experiments seems to me quite unwarranted.

The second series comprised 4 monkeys injected with very large quantities of typhus serum ( 6 to 18 c.c.), 1 with unfiltered, 3 with filtered virus. None reacted to the injection. Subsequently 1 monkey which had been injected with filtered serum and 1 which had been injected with unfiltered serum were reinoculated with virulent blood. Both came down with the disease! Here again, the controls were unsatisfactory and the blood used for the first injection may have been avirulent.

The third series included the injection of a man (one of the co-workers of Nicolle) with 0.25 c.c. of filtered typhus serum. There was no reaction and the control monkey died of some intercurrent disease shortly after inoculation. This series as well leads to no conclusion.

The fourth series is relatively unimportant since the only conclusion to be drawn therefrom is that filtered emulsions of disintegrated leukocytes from virulent blood did not infect a monkey.

The fifth series of experiments ${ }^{11}$ comprised 2 monkeys injected with filtered blood, which did not react and were not immunized - a typical experiment leading to only one conclusion; namely, that the virus does not pass through the filter.

From Nicolle's work we may conclude that he has presented no evidence that typhus fever virus is filtrable.

To support Nicolle's assumption of the filtrability of the typhus

10 Bull. 86, Hyg. Lal., Washington, 1). C., 1912.

1 Nicolle, Blanc and Conseil, Arch. de l'Inst. Pasteur de Tumis, 1914, 9, p. 84. 
virus, the observers mentioned added the single experiment of Wilder, ${ }^{3}$ who continued the work of Ricketts and Wilder. ${ }^{12}$ All their experiments in regard to the filtrability of virus may be classed into 3 series.

The first series comprised 2 monkeys. One monkey, injected with unfiltered blood, died of typhus fever; one monkey injected with filtered blood showed no reaction. The conclusion of Ricketts and Wilder was: "It seems probable, therefore, that the virus of the typhus fever of Mexico may be classed with the unfiltrable."

The second series, comprising 2 monkeys, showed the same results. Here, as well, was demonstrated the absence of immunity in the monkey injected with filtered blood mentioned in the first series. The authors' conclusion was: "The evidence is sufficiently strong that the virus of tabardillo [Mexican typhus fever] does not pass through a filter of the type mentioned [Berkefeld]."

$\mathrm{Up}_{\mathrm{p}}$ to this point a definite case for the nonfiltrability of the typhus virus has been made out.

The third series, however, did not confirm the other two. This series completed the second: both the monkey which had been injected with unfiltered blood, and the one injected with filtered blood, were immune. Wilder explains this refractoriness on the part of the monkey injected with filtered blood on the basis that the monkey was naturally immune, or that certain substances passed through the filter which immunized the animal, or that at one stage of the disease the organisms are filtrable.

The only conclusion to be drawn from Wilder's experiment is that the monkey was naturally immune or that avirulent blood was used in the immunity test. The great number of experiments showing that filtered blood neither infects nor immunizes, that a large proportion of monkeys are naturally immune to typhus virus, and the fact that Wilder injected his animal only once, when a second or third injection sometimes is necessary to produce typhus fever - speak against any other conclusion.

Hence, neither of these two observers, Nicolle nor Wilder, has presented sufficient evidence that typhus virus is filtrable.

On the other hand, definite, decisive, and controlled experiments have shown that typhus virus is nonfiltrable. These have been made by Anderson and Goldberger ${ }^{10}$ by Gaviño and Girard, ${ }^{13}$ and by myself.

The classical experiments of Anderson and Goldberger may be

12 Jour. Am. Med. Assn., 1910, pp. 463, 1373.

13 Pub. de l'Inst. Bacteriol. Nacionale de México, 1910 (Aug. 23 and Nov. 9) and 1911 (Nov. 12). 
grouped into 3 series. The first series comprised 4 monkeys. Two were injected with unfiltered typhus serum; one reacted, while the other did not react to this injection, but did react to a subsequent inoculation. Two monkeys were injected with the same serum filtered; neither reacted, nor were they immunized.

The second series comprised 4 monkeys. The resuits were identical with those of the first series.

The third series comprised 2 monkeys which were injected with the filtered serum from clotted typhus blood - the blood having been centrifugated. They did not react nor were they immunized. These experiments remove the main objections of Nicolle, who stated that the virus is intraleukocytic and unless clotted whole typhus blood is used after centrifugation (so as to break up some leukocytes), the results may be negative.

From these experiments Anderson and Goldberger conclude: ". . . there is no evidence that the virus in the blood of typhus is able to pass the Berkefeld filter."

Gaviño and Girard carried out experiments which correspond to the fourth series of Nicolle's work. They injected intraperitoneally into a monkey at the height of its typhus fever, peptone broth. Three hours later the peritoneal fluid, rich in red and white blood cells, was removed. A filtrate of this failed to infect a monkey and, as a result, they conclude that the virus is nonfiltrable.

I wish now to present further evidence demonstrating the nonfiltrability of typhus virus - the result of experiments suggested by Dr. Libman. He advised the use of guinea-pigs for this work for the following reasons. While natural immunity against typhus occurs in a great percentage of monkeys, this condition is almost unknown in mature guinea-pigs. Baehr ${ }^{1}$ found that when guinea-pigs failed to react to an injection of typhus virus, the refractoriness was not due to the immunity of the animal but rather to a lack of infectivity of the blood. For instance, when a guinea-pig failed to react, all guinea-pigs in the same series, that is, all injected with the same blood, failed to react. Anderson ${ }^{14}$ in a series of 210 guinea-pigs found that only $4.7 \%$ failed to react to what he regarded as virulent blood. But in all these no subsequent immunity tests were made; all might have reacted to a second or even a third injection of virus. Hence we see that guineapigs are peculiarly fitted for experiments on the filtrability of the virus.

14 Jour. Med. Research, 1914, 25, p. 467. 


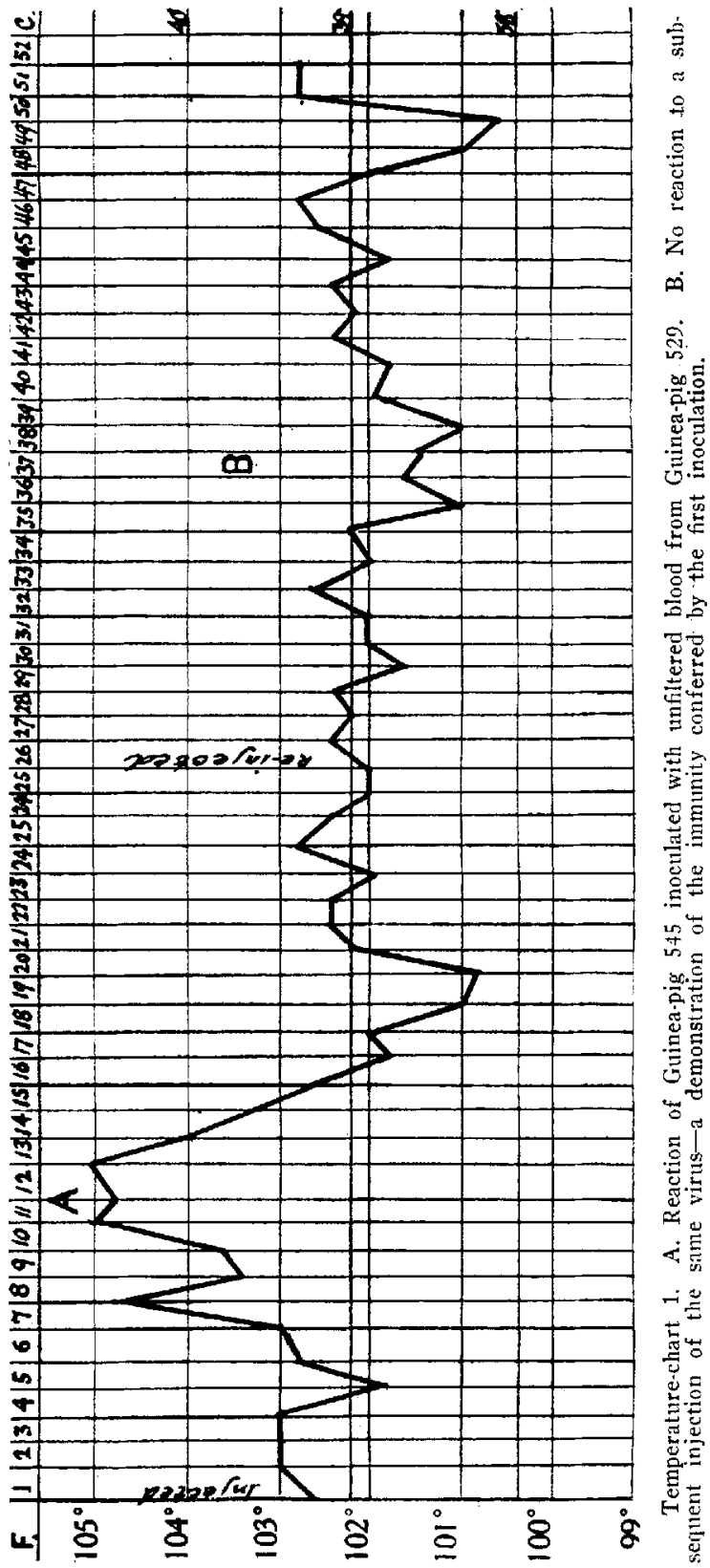




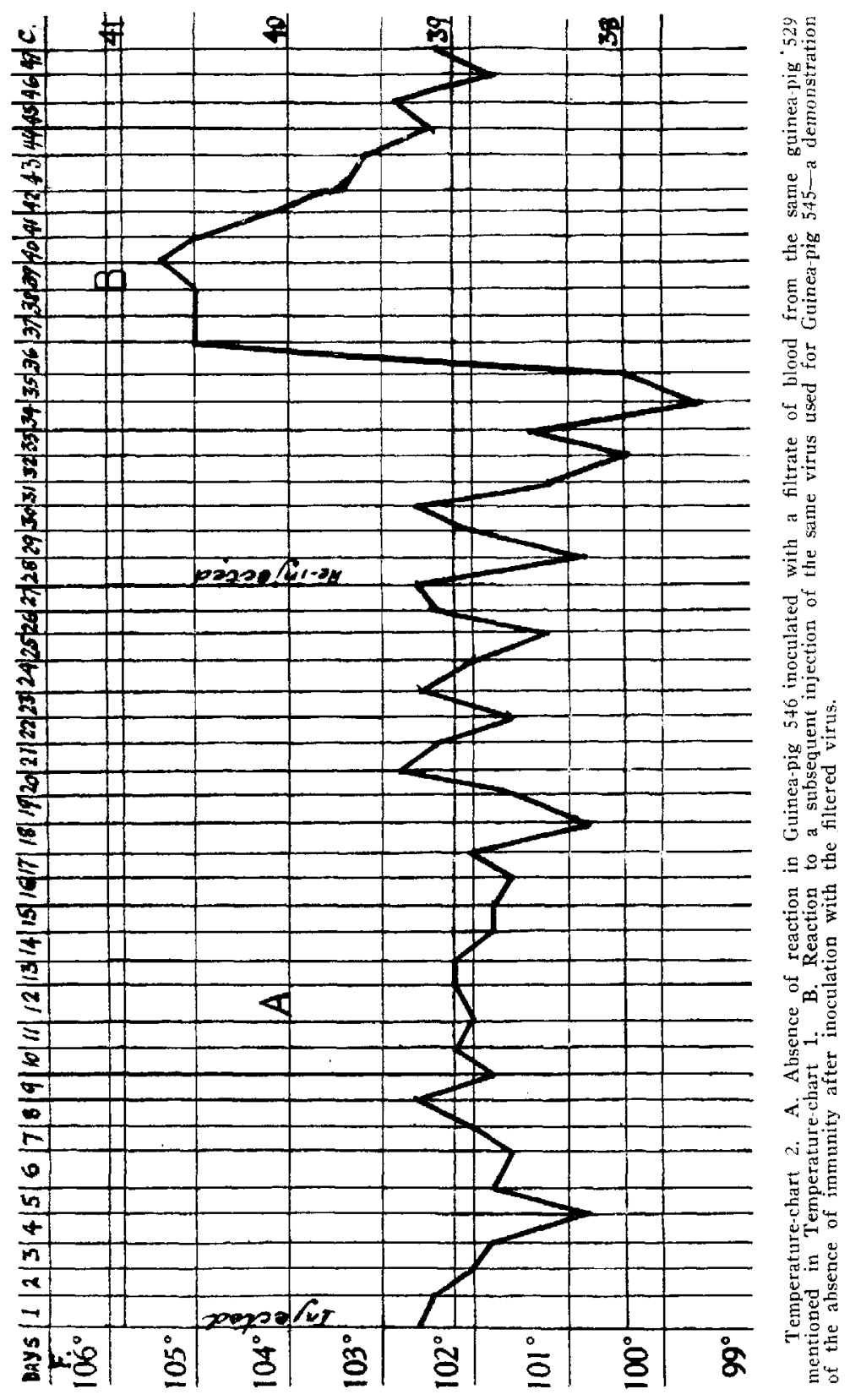


In my experiments all factors which would tend to interfere with the results were carefully eliminated. The virus employed was one which had been obtained originally from a case of endemic typhus fever and had been transmitted for about 5 years from guinea-pig to guinea-pig. Its incubation period was more or less constant - about 10 days; the duration of the fever was usually from 4 to 6 or 7 days. In each series of experiments, the same blood was used throughout; the unfiltered blood was obtained from the material left on the outer side of the candle; the filtered blood, from what passed through. The filter was of the Berkefeld type, size $\mathrm{N}$, which does not allow the passage of Bacillus typhosus, Micrococcus aureus, Bacterium coli, Streptococcus anhemolyticus, or the typhus bacillus. The filters were new and the whole apparatus was sterilized in moist steam. The pressure employed was $500 \mathrm{~mm}$. $\mathrm{Hg}$ and the time taken in the filtration was within one-half hour.

The blood was prepared for filtration as follows: A guinea-pig was exsanguinated at the height of a typhus-fever reaction. The whole blood was defibrinated and cleared by centrifugation. The serum (which carries the virus) was diluted with twice its volume of physiologic salt solution to prevent clogging of the filter. For the subsequent immunity test, whole defibrinated blood containing the same strain of virus was used.

Guinea-pig 545 (see Temperature-chart 1) was inoculated intraperitoneally with an amount of unfiltered diluted serum from typhus Guinea-pig 529, equivalent to 2 c.c. of the whole serum. Eleven days later, the animal developed a fever of over $40 \mathrm{C}$. (104 F.) lasting for 4 days; then the crisis occurred. After 11 days of normal temperature, the animal was reinoculated with virus from a typhus-fever guinea-pig (4 c.c. of defibrinated blood from Guinea-pig 572); there was no reaction, tho 3 c.c. of the same blood gave rise to the fever in a control guinea-pig (No. 577) after an incubation period of 10 days.

In other words, the unfiltered blood gave rise to typhus fever which immunized the animal against a subsequent injection of the virus.

Guinea-pig 546 (see Temperature-chart 2) was inoculated with the filtrate of the same serum used for Guinea-pig 545. An amount equivalent to 4 c.c. of the whole serum was injected intraperitoneally. There was no reaction for 28 days; at the end of this time the animal was inoctulated with one-half the amount ( 2 c.c.) of the same virus (from Guinea-pig 529) used for Guinea-pig 545. After an incubation period of 9 days, the animal developed typhus fever lasting 6 days. 
In other words, the filtered virus neither produced the disease nor immunized the animal.

Upon repetition of these experiments the same results were obtained.

\section{CONCLUSIONS}

The most favorable animal for the study of the filtrability of typhus blood is the guinea-pig. In the experiments here reported, it has been conclusively demonstrated that the infective agent of typhus fever belongs to the group of nonfiltrable viruses. This agrees with the previous observation that Bacillus typhi-exanthenatici is nonfiltrable. 